\title{
VALIDATED MICROBIOLOGICAL AND HPLC METHODS FOR THE DETERMINATION OF MOXIFLOXACIN IN PHARMACEUTICAL PREPARATIONS AND HUMAN PLASMA
}

\author{
Ahmed A. Abdelaziz, Tarek E. Elbanna, Noha M. Gamaleldeen* \\ Department of Pharmaceutical Microbiology, Faculty of Pharmacy, University of Tanta, Tanta, Egypt.
}

Submitted: April 04, 2011; Returned to authors for corrections: November 17, 2011; Approved: June 07, 2012.

\begin{abstract}
The article presents a comparison between microbiological and high performance liquid chromatographic (HPLC) assays for quantification of moxifloxacin in tablets, ophthalmic solutions and human plasma. The microbiological method employed a cylinder-plate agar diffusion assay using a strain of Esherichia coli ATCC 25922 as the test organism and phosphate buffer (pH8) as the diluent. The calibration curves were linear $\left(\mathrm{R}^{2}>0.98\right)$ over a concentration range of 0.125 to $16 \mu \mathrm{gml}^{-1}$. The within day and between days precisions were $\leq 4.47 \%$ and $\leq 6.39 \%$ respectively. Recovery values were between 89.4 and $110.2 \%$. The HPLC assay used Hypersil ${ }^{\circledR}$ BDS $C_{18}$ reversed phase column $(250 \times 4.6 \mathrm{~mm}, 5 \mu \mathrm{m})$ with a mobile phase comprising $20 \mathrm{mM}$ ammonium dihydrogen orthophosphate $(\mathrm{pH} 3)$ and acetonitrile $(75: 25)$ and flowing at $1.5 \mathrm{ml} / \mathrm{min}$. The detection was at $295 \mathrm{~nm}$. The calibration curves were linear $\left(\mathrm{R}^{2}>0.999\right)$ over the range of 0.125 to $16 \mu \mathrm{g} \mathrm{ml}^{-1}$. The within day and between days precisions were $\leq 4.07 \%$ and $\leq 5.09 \%$ respectively. Recovery values were between 97.7 and $107.6 \%$. Similar potencies were obtained after the analysis of moxifloxacin tablets and ophthalmic solutions by both methods. Also pharmacokinetic parameters were calculated after the analysis of plasma samples of six male healthhy volunteers by both validated methods.
\end{abstract}

Key words: Moxifloxacin; Microbiological assay; HPLC assay; Pharmaceutical analysis; Pharmacokinetics.

\section{INTRODUCTION}

Since the mid-1980s, the fluoroquinolones (FQs) have become a major group of synthetic antibiotics with activity that ranges from the Enterobacteriaceae and opportunists such as Pseudomonas aeruginosa, to Gram-positive pathogens, including streptococci and staphylococci (4). Moxifloxacin
(4aS-cis)-1-Cyclopropyl-6-fluoro-1,4-dihydro-8-methoxy-7(octahydro-6H-pyrrolo[3,4-b]pyridin-6-yl)-4-oxo-3-

quinolinecarboxylic acid, monohydrochloride (Fig.1) (29) is a new fourth generation 8-methoxy FQ developed primarily for the treatment of community acquired pneumonia and upper respiratory tract infections (3). It was also approved for the prevention and treatment of serious ophthalmic infections (e.g. 
keratitis and endophthalmitis) caused by susceptible bacteria (23). Moxifloxacin is well absorbed from the gastrointestinal tract with absolute bioavailability of approximately $90 \%$. It is $30-50 \%$ bound to serum proteins, independent of drug concentration and is widely distributed throughout the body, with tissue concentrations often exceeding plasma concentrations. The pharmacokinetics of moxifloxacin were found to be linear with a wide range of single oral and parental doses from 50 to $800 \mathrm{mg}$. Maximum plasma concentration $\left(0.29-4.73 \mathrm{mgL}^{-1}\right)$ is reached after $0.5-4 \mathrm{hr}(18,24)$.

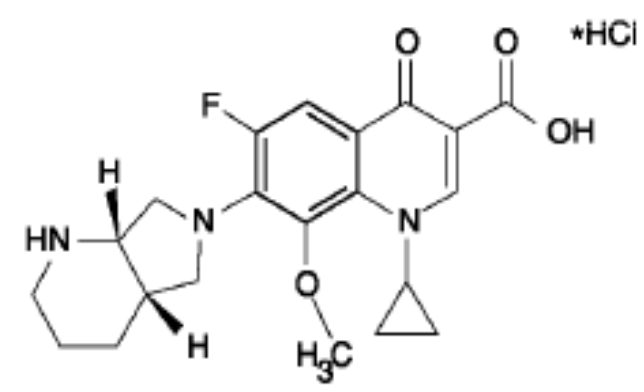

Figure 1. Chemical structure of moxifloxacin hydrochloride (USP number 186826-86-8)

The activity (potency) of antibiotics may be demonstrated under suitable conditions by their inhibitory effect on microorganisms. A reduction in antimicrobial activity will also reveal subtle changes not demonstrable by chemical methods (30). However the assay methodology has changed to chromatographic assays for many antibiotics as they provide quantitative measurements of the purity and the amounts and types of impurities in antibiotics. Nevertheless, a number of commercially important antibiotics continue to require potency determination by microbiological assays (9).

Guerra et al. (11) described a biological assay for analysis of moxifloxacin in tablets. In contrast, several chemical methods for quantitative determination of moxifloxacin in pharmaceutical formulations and biological fluids were described in scientific literature including capillary electrophoresis with laser-induced fluorescence (21), square- wave adsorptive voltammetery (26), spectrophotometery (20), spectrofluorimetery (28), high-performance liquid chromatography $(7,13,19,22,25,31)$ amongst others, and ultra HPLC (17). Officially moxifloxacin hydrochloride and moxifloxacin ophthalmic solution were assayed chromatography by an HPLC assay (29) .

Method validation is the process that confirms that the analytical procedure employed for a specific test is suitable for its intended use, and it is the corner stone in using the method to evaluate drugs in pharmaceutical industrial committees and regulatory agencies (15). Thus, the scope of this study was to develop and validate an agar diffusion method and HPLC method through the parameters of linearity, precision and accuracy to determine the potency of moxifloxacin in different pharmaceutical formulations as well as monitor the pharmacokinetic parameters of the drug through the analysis of human plasma samples.

\section{EXPERIMENTAL}

\section{Materials}

Moxifloxacin hydrochloride reference substance (Bayer chemical, Germany) was supplied by Alkan Pharma, Egypt. Avalox ${ }^{\circledR}$ tablet (400 mg moxifloxacin) and Vigamox ${ }^{\circledR}$ sterile ophthalmic solution (5 $\mathrm{mg}$ moxifloxacin in each $\mathrm{ml}$ ) were purchased from the Egyptian markets. Dipotassium hydrogen phosphate and potassium dihydrogen phosphate (BDH, England) were used for buffer preparation. Antibiotic medium No.1 (Difco, England) was purchased for the microbiological assay. Acetonitrile and methanol of HPLC grade (MERCK, Germany), ammonium dihydogen orthophosphate and tinidazole (Reidel de Haein, Germany) were used for the HPLC assay. Water used was double distilled and of high purity.

\section{Methods}

Preparation of standard solutions: Moxifloxacin 400 $\mu \mathrm{gml}^{-1}$ stock solution was prepared by dissolving appropriate amount of moxifloxacin hydrochloride (equivalent to $20 \mathrm{mg}$ 
moxifloxacin) in phosphate buffer $0.1 \mathrm{M}(\mathrm{pH} 8)$. The working standards of moxifloxacin in concentrations of 2.0, 4.0 and 8.0 $\mu \mathrm{gml}^{-1}$ were prepared in the same buffer and used for analysis of moxifloxacin in tablet and ophthalmic solution. In addition, eight working standards in the concentration range of 0.125 to $16.0 \mu \mathrm{gml}^{-1}$ were prepared in human blank plasma. These were employed in the method validation and were used to monitor the pharmacokinetic parameters of the drug.

\section{Microbiological condition:}

- Organism and inoculum: The cultures of E.coli ATCC 25922 were cultivated on MacConkey' agar and kept in the refrigerator then pealed to nutrient agar and incubated at $37^{\circ} \mathrm{C}$ under aerobic condition $24 \mathrm{hr}$ before the assay. A bacterial suspension having a transmittance of $75 \% \pm 2 \%$ (equivalent to $0.125 \pm 0.01$ optical density) at $620 \mathrm{~nm}$ was prepared in saline. Portions of $0.5 \mathrm{ml}$ of the inoculated saline were added to $20 \mathrm{ml}$ of antibiotic medium No. 1 at $48{ }^{\circ} \mathrm{C}$ to $50^{\circ} \mathrm{C}$ and used as the inoculated layer.

- Cylinder-plate assay: The agar plate was composed of two separate layers. Twenty milliliter of antibiotic medium No. 1 agar was poured into $(100 \times 20 \mathrm{~mm})$ sterile Petri dishes as the base agar. After solidification, portions of $5 \mathrm{ml}$ of the inoculated layer were poured onto the base layer. In each agar plate six stainless steel cylinders $(8 \times 6 \times$ $10 \mathrm{~mm}$ ) were placed on the surface of inoculated medium, before loading with $200 \mu \mathrm{l}$ of standard or sample solutions. After incubation at $37^{\circ} \mathrm{C}$ for $18 \mathrm{hr}$, the zone diameters of the growth inhibition were measured in $(\mathrm{mm})$ using a digital caliper. For the analysis of plasma samples Petri dishes of size (150 $\mathrm{mm} \times 20 \mathrm{~mm}$ ) were used and the base layer comprised of $40 \mathrm{ml}$ aliquots of antibiotic medium No. 1, onto which $15 \mathrm{ml}$ aliquots of the inoculated medium were poured.

Chromatographic condition: An HPLC system equipped with a variable wavelength UV detector and an automatic injector was used in this study (LC - $10 \mathrm{VP}$, Shimadzu Scientific Instrument). Separation was accomplished at ambient temperature on a $250 \mathrm{~mm} \times 4.6 \mathrm{~mm}, 5 \mu$ Hypersil $^{\circledR}$ BDS $\mathrm{C}_{18}$ column. The mobile phase consisted of $20 \mathrm{mM}$ Ammonium dihydrogen orthophosphate solution ( $\mathrm{pH}$ adjusted to 3 ) and acetonitrile (75:25) and the flow rate was $1.5 \mathrm{ml} / \mathrm{min}$. The effluent was detected at $295 \mathrm{~nm}$ and the peak areas were calculated utilizing the data analysis program class - VP (Shimadzu Scientific Instrument).

Method validation: Both microbiological and HPLC methods were validated according to the FDA industrial guidance for bioanalytical method validation (27).

- Linearity of the calibration curves: Calibration curves of eight concentrations ranging from 0.125 to $16 \mu \mathrm{gml}^{-1}$ of moxifloxacin in pooled human plasma were conducted daily. The linearity was determined by computing linear least-square regression of the: a- Square of the inhibition zone diameters (y) versus the logarithm of moxifloxacin concentration in the microbiological assay, b- Peak area ratio drug/internal standard (y) versus moxifloxacin concentration in the HPLC assay.

- Accuracy and precision: Both within day and between days accuracy and precision were considered. Within day accuracy and precision of the assay were determined by the analysis of five replicates of the eight concentrations from 0.125 to $16 \mu \mathrm{gml}^{-1}$ in the same day. For the between days accuracy and precision at least six replicates on six different days during the study period were measured. The \% recovery of the back calculated concentrations were compared to the nominal concentrations to determine the accuracy of the assay while the relative standard deviation (RSD) was used to determine the precision of the assay.

- Quantitation limit: The lowest limit of quantification (LOQ) was taken as the concentration 
- giving a 5 times the response obtained from the blank (if any) or the concentration which is detectable and quantifiable with a precision less than $20 \%$ and accuracy of $80-120 \%$.

- Selectivity: Selectivity was assessed by examining the interference from endogenous substances \& buffer solutions.

Quality control samples: The performance of the assay during the analysis of the study samples was evaluated by analysis of three independent low, middle and high concentrations $\left(0.3,3,9 \mu \mathrm{gml}^{-1}\right)$. These were incorporated in each analysis run and were treated as the unknown samples. The recovery of QC samples determined from the calibration curve and the back calculated concentrations was compared with the nominal values.

Determination of moxifloxacin in tablets and ophthalmic solutions: Three tablets were individually pulverized; transferred to $100 \mathrm{ml}$ volumetric flasks with phosphate buffer( $\mathrm{pH} 8$ ), shaken for $10 \mathrm{~min}$ before adjusting the volume. These were suitably diluted to obtain final concentrations of 2, 4 and $8 \mu_{\mathrm{gml}^{-1}}$. For the ophthalmic solution, three bottles were employed with $1 \mathrm{ml}$ sample being taken from each. These were diluted with the same buffer and three concentrations were prepared as in case of tablets.

\section{Determination of the pharmacokinetic parameters of} moxifloxacin: The study protocol was approved by FPTU's REC (Faculty of Pharmacy Tanta University Research Ethics Committee). The volunteers were informed by the details of the study and a written concert was obtained from each. The study employed six healthy male volunteers (21-26 years old) with a body weight of $60-75 \mathrm{~kg}$. Each person was given a single oral dose $(400 \mathrm{mg})$ of the drug. Plasma samples were collected in heparinized tubes at predetermined time intervals from 0 to 48 hrs after drug administration. Plasma was separated by centrifugation and stored at $-20{ }^{\circ} \mathrm{C}$. For the microbiological analysis, samples were thawed and vortexed for 30 second, then three replicates of $200 \mu \mathrm{l}$ volumes from each sample were directly introduced into the assay. For HPLC analysis $250 \mu \mathrm{l}$ of each sample was transferred to a clean test tube; spiked with 25 $\mu 1$ of the internal standard $\left(250 \mathrm{\mu gml}^{-1}\right.$ tinidazole stock solutions), treated with $0.5 \mathrm{ml}$ methanol, shaked for 30 seconds, and centrifuged at $1006 \times g$ for $7 \mathrm{~min}$. A portion of the supernatant $(25 \mu \mathrm{l})$ was then injected into the HPLC system.

\section{Calculations}

To calculate the activity (potency) of moxifloxacin in pharmaceutical preparations microbiologically, symmetrical three dose levels assay and the Hewitt equation were used (14). The calculation was based on the assumption of two straight parallel lines, one being a plot of responses to standard against the logarithm of dose and the other being a plot of responses to unknown against the logarithm of nominal dose. Regression analysis of the slopes of the two lines was used to verify that there was no deviation from parallelism. The quantitative determination of moxifloxacin in commercial samples by HPLC was carried out using the equation of linear regression of the calibration curves. Also analysis of plasma samples by both methods was carried out by the use of regression equation of the calibration curves then the pharmacokinetic parameters $\mathrm{C}_{\max }, \mathrm{T}_{\max }, \mathrm{AUC}_{0 \rightarrow \infty}$ and $\mathrm{T}_{1 / 2}$ were calculated following a non compartment pharmacokinetic approach (12).

\section{RESULTS AND DISCUSSION}

Despite of the existence of alternative methods for determination of moxifloxacin $(7,13,19,21,25,26,28,31)$ only few of them employed the microbiological assay. Even the reported microbiological assays were not fully validated (11). The current study compared the validity of HPLC versus the microbiological assay for determination of moxifloxacin both in pharmaceutical formulations and biological fluids.

Methods validation

The microbiological and HPLC methods were validated according to the FDA guidance and satisfied all requirements for bioanalytical method validation (27). The validation procedures were carried out in human plasma as biological 
matrix and the following fundamental parameters were studied:

Linearity of the calibration curves: The calibration curves were linear in the range of concentrations of 0.125 to
$16 \mu \mathrm{gml}^{-1}$ and the individual $\left(\mathrm{R}^{2}\right)$ values were always $\geq 0.98$ for the microbiological assay and $\geq 0.999$ for the HPLC assay (Fig.

2).

A)
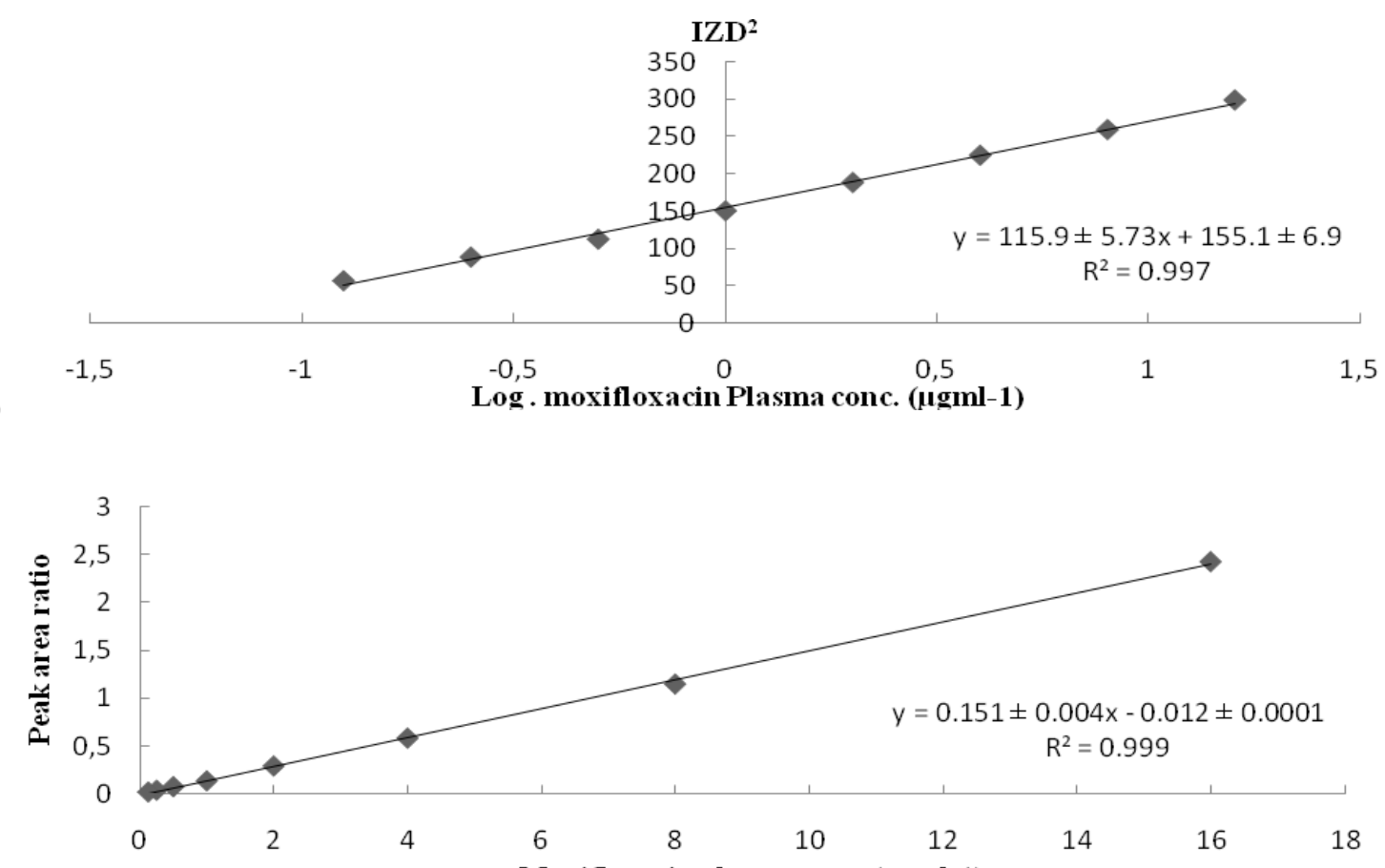

B)

Moxifloxacin plasma conc. ( $\mu \mathrm{gml}-1)$

$\mathrm{IZD}^{2}$ : inhibition zone diameter square.

Figure 2. Mean of six standard curves of moxifloxacin in human plasma as determined by the microbiological and HPLC methods (panels A and B respectively).

Accuracy and precision: Within day and between days accuracy values were in the range of $89.4-110.2 \%$ and $97.7-$ $107.6 \%$ as determined by the microbiological assay and HPLC respectively. Whereas, Within day and between days precision values were in the range of $2.02-6.39 \%$ and $1.25-5.09 \%$ as determined by the microbiological assay and HPLC respectively (Tables 1,2). These results indicate that both methods are accurate and precise (27).

Table 1. Within day and between days accuracy and precision of the microbiological assay

\begin{tabular}{|c|c|c|c|c|c|c|}
\hline \multirow{2}{*}{ Nominal conc. $\left(\mu \mathrm{gml}^{-1}\right)$} & \multicolumn{2}{|c|}{ Found conc. $\left(\mu \mathrm{gml}^{-1}\right) \pm$ S.D. } & \multicolumn{2}{|c|}{ RSD } & \multicolumn{2}{|c|}{$\%$ of found conc. } \\
\hline & Within day $^{(\mathrm{a})}$ & Between days $^{(\mathbf{b})}$ & Within day $^{(a)}$ & Between days $^{(\mathbf{b})}$ & Within day $^{(\mathrm{a})}$ & Between days $^{(\text {b) }}$ \\
\hline 0.125 & $0.136 \pm 0.004$ & $0.138 \pm 0.01$ & 2.65 & 5.37 & 108.8 & 110.2 \\
\hline 0.25 & $0.254 \pm 0.01$ & $0.265 \pm 0.02$ & 3.94 & 6.39 & 101.8 & 106.1 \\
\hline 0.5 & $0.453 \pm 0.01$ & $0.454 \pm 0.02$ & 2.41 & 5.48 & 90.6 & 90.8 \\
\hline 1 & $0.894 \pm 0.02$ & $0.922 \pm 0.04$ & 2.72 & 4.05 & 89.4 & 92.2 \\
\hline 2 & $2.019 \pm 0.09$ & $1.979 \pm 0.08$ & 4.47 & 4.10 & 100.9 & 98.9 \\
\hline 4 & $3.953 \pm 0.17$ & $4.166 \pm 0.24$ & 4.19 & 5.83 & 98.8 & 104.2 \\
\hline 8 & $7.957 \pm 0.35$ & $8.011 \pm 0.34$ & 4.36 & 4.26 & 99.5 & 100.1 \\
\hline 16 & $16.89 \pm 0.34$ & $17.21 \pm 0.78$ & 2.02 & 4.53 & 105.6 & 107.6 \\
\hline
\end{tabular}


Table 2. Within day and between days accuracy and precision of the HPLC assay

\begin{tabular}{|c|c|c|c|c|c|c|}
\hline \multirow{2}{*}{ Nominal conc. $\left(\mu \mathrm{gml}^{-1}\right)$} & \multicolumn{2}{|c|}{ Found conc. $\left(\mu \mathrm{gml}^{-1}\right) \pm$ S.D. } & \multicolumn{2}{|c|}{ RSD } & \multicolumn{2}{|c|}{$\%$ of found conc. } \\
\hline & Within day ${ }^{(\mathbf{a})}$ & Between days $^{(b)}$ & Within day $^{(\mathrm{a})}$ & Between days $^{(\mathbf{b})}$ & Within day ${ }^{(a)}$ & Between days ${ }^{(b)}$ \\
\hline 0.125 & $0.133 \pm 0.005$ & $0.135 \pm 0.005$ & 3.42 & 3.48 & 106.7 & 107.6 \\
\hline 0.25 & $0.253 \pm 0.01$ & $0.248 \pm 0.01$ & 4.07 & 5.09 & 101.3 & 99.2 \\
\hline 0.5 & $0.518 \pm 0.02$ & $0.505 \pm 0.02$ & 3.23 & 3.57 & 103.6 & 101.0 \\
\hline 1 & $0.995 \pm 0.03$ & $0.977 \pm 0.04$ & 3.46 & 3.59 & 99.6 & 97.7 \\
\hline 2 & $2.063 \pm 0.06$ & $2.067 \pm 0.05$ & 2.71 & 2.43 & 103.1 & 103.3 \\
\hline 4 & $4.143 \pm 0.11$ & $4.110 \pm 0.16$ & 2.75 & 3.91 & 103.6 & 102.7 \\
\hline 8 & $7.837 \pm 0.18$ & $7.875 \pm 0.15$ & 2.36 & 1.85 & 97.9 & 98.4 \\
\hline 16 & $16.04 \pm 0.22$ & $15.98 \pm 0.20$ & 1.35 & 1.25 & 100.3 & 99.8 \\
\hline
\end{tabular}

Quantitation limit: The lower limit of quantitation of moxifloxacin by both methods was $0.125 \mu \mathrm{gml}^{-1}$ at which the response was identifiable, discrete, and reproducible with a precision of less than $10 \%$ and an accuracy of $80-120 \%$. This limit provided sufficient coverage of the in vitro and in vivo application of the methods.

Selectivity: Applying blank plasma and buffer solution samples in the analysis procedures did not show any interference with the original drug responses indicating selectivity of the proposed microbiological (Fig. 3) and HPLC (Fig. 4) methods. This reflects the suitability of the developed methods for determination of the drug in human plasma and makes the methods suitable for monitoring drug bioavailability.

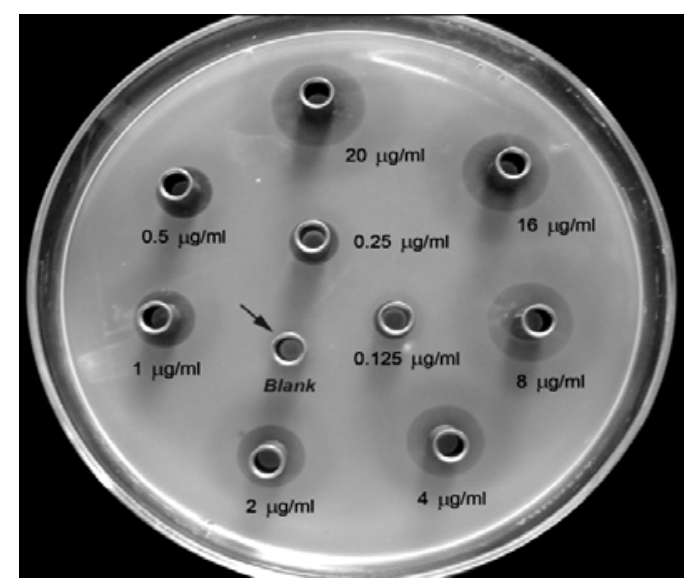

The arrow show blank plasma with no zone of inhibition under the developed experimental conditions.

Figure 3. Selectivity of the microbiological assay

A)
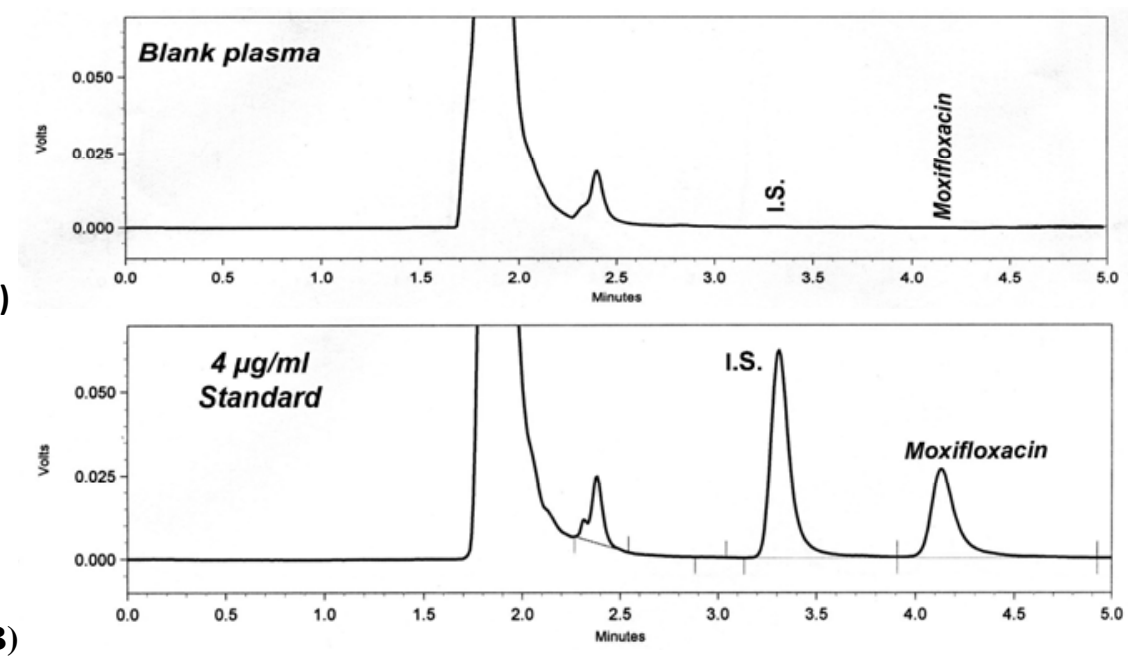
C)

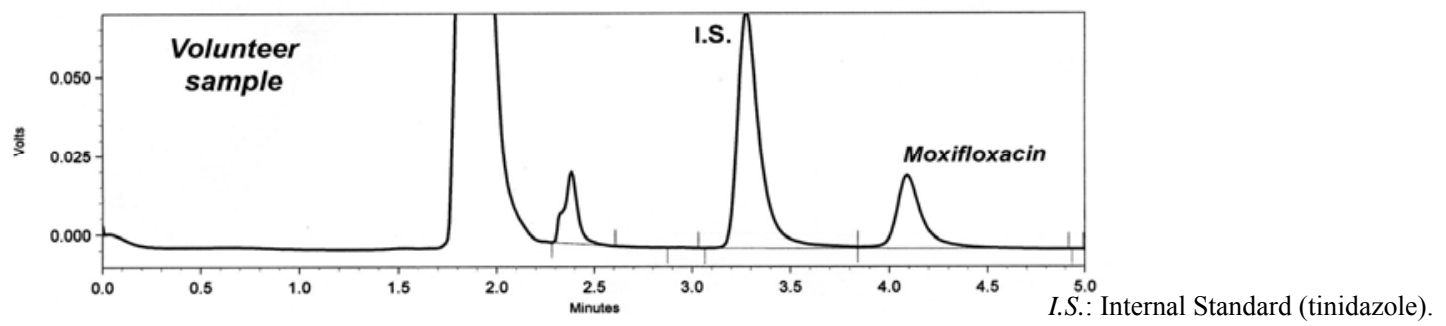

Figure 4. Representative chromatograms for, (A): blank plasma sample, (B): blank plasma spiked with moxifloxacin to produce drug concentration of $4 \mu \mathrm{g} / \mathrm{ml}$ and internal standard, and $(\mathrm{C})$ : plasma sample that was obtained $1.5 \mathrm{hr}$ after administration of Avalox ${ }^{\circledR}$ tablet to volunteer \# 1

Quality control samples: The recorded data revealed good recovery for all the tested concentrations. This is indicated from the obtained values which were in the range of $97.93-113.3 \%$ and $99.48-105.7 \%$ of the nominal values in cases of the microbiological and HPLC methods respectively
(Table 3). These results comply with the acceptance criteria which require that at least $67 \%$ of the QC samples must not deviate by more than $15 \%$ of the corresponding nominal value with a possibility that $33 \%$ of the samples being outside this range (27).

Table 3. Recovery of quality control samples of moxifloxacin as determined by microbiological and HPLC methods

\begin{tabular}{|c|c|c|c|c|}
\hline \multirow{2}{*}{$\begin{array}{c}\text { Nominal } \\
{\text { conc. } \text { pgml }^{-1}}^{\text {Non }}\end{array}$} & \multicolumn{2}{|c|}{ Found conc. ${ }^{\mathrm{a}} \mu \mathrm{gml}^{-1} \pm$ S.D. } & \multicolumn{2}{|c|}{ \% of found conc. } \\
\hline & Microbiological & HPLC & Microbiological & HPLC \\
\hline 0.3 & $0.34 \pm 0.023$ & $0.32 \pm 0.019$ & 113.3 & 105.7 \\
\hline 3 & $2.94 \pm 0.212$ & $3.01 \pm 0.170$ & 97.93 & 100.4 \\
\hline 9 & $9.45 \pm 0.425$ & $8.95 \pm 0.373$ & 105.05 & 99.48 \\
\hline
\end{tabular}

$\overline{\mathrm{a}} \mathrm{n}=10$ for each concentration

S.D. = standard deviation

\section{Determination of moxifloxacin in tablets and ophthalmic} solutions

Microbiological method: An experimental $3 \times 3$ design, using three dose levels $\left(2,4\right.$ and $\left.8 \mu \mathrm{gml}^{-1}\right)$ for each standard and sample were analyzed as 6 replicates of each dose level $(2,8)$. The log dose-response line recorded for the tested samples was parallel to that obtained for the authentic standard concentrations. As a pre request for application of the parallelline model $(2,8)$, these findings were verified by means of statistical regression analysis of the slopes of the parallel-lines.
Results showed that the two lines were linear with no deviation from parallelism at 95\% confidence levels.

Accordingly, the Hewitt equation (14) was employed in calculation of the potency of the drug in the tested formulations. The results are presented in table 6 . The results indicated the suitability of the microbiological assay for determination of drug concentration in dosage forms with RSD value of $1.38 \%$ between Avalox ${ }^{\circledR}$ samples and $0.40 \%$ between Vigamox ${ }^{\circledR}$ samples (Table 4).

Table 4. Potency obtained in the analysis of moxifloxacin in its dosage forms using the microbiological method

\begin{tabular}{|c|c|c|c|c|c|c|c|}
\hline \multicolumn{4}{|c|}{ Avalox ${ }^{\circledR}$ tablets } & \multicolumn{4}{|c|}{ Vigamox $^{\circledR}$ ophthalmic solution } \\
\hline Sample $^{\mathbf{a}}$ & Experimental amount (mg) & \%Level & RSD & Sample $^{c}$ & Experimental amount (mg) & \%Level & RSD \\
\hline 1 & 410.48 & 102.62 & & 1 & 5.034 & 100.7 & \\
\hline 2 & 399.55 & 99.89 & 1.38 & 2 & 5.000 & 99.96 & 0.40 \\
\hline
\end{tabular}


HPLC: The recovered drug values were calculated from the calibration curves which were constructed as before. The results of the determination of moxifloxacin in Avalox ${ }^{\circledR}$ tablets \& Vigamox ${ }^{\circledR}$ ophthalmic solution are summarized in Table 5. The method was shown to be precise with RSD values of $1.83 \%$ between Avalox ${ }^{\circledR}$ samples and $0.66 \%$ between

\section{Vigamox ${ }^{\circledR}$ samples.}

The efficiency of both methods in determination of drug content of tablets and eye drops was compared. This was achieved using the Student $t$ test. Results revealed similar efficacy as indicated from the non-significant difference between the revealed values $(\mathrm{P}>0.05)$.

Table 5. The results obtained in the analysis of moxifloxacin in its dosage forms using the HPLC method

\begin{tabular}{|c|c|c|c|c|c|c|c|}
\hline \multicolumn{3}{|c|}{ Avalox ${ }^{\circledR}$ tablets } & & \multicolumn{4}{|c|}{ Vigamox $^{\circledR}$ ophthalmic solution } \\
\hline Sample $^{\mathrm{a}}$ & Experimental amount (mg) & \%Level & RSD & Sample $^{c}$ & Experimental amount (mg) & \%Level & RSD \\
\hline 1 & 412.96 & 103.2 & & 1 & 4.993 & 99.88 & \\
\hline 2 & 403.07 & 100.8 & 1.83 & 2 & 5.050 & 101.0 & 0.66 \\
\hline 3 & 417.82 & 104.5 & & 3 & 5.053 & 101.1 & \\
\hline
\end{tabular}

${ }^{\mathrm{a}}$ Theoretical amount: $400 \mathrm{mg}$ per tablet. $\quad{ }^{\mathrm{b}}$ Each value is the mean of 6 analyses.

${ }^{\mathrm{c}}$ Theoretical amount: Each $\mathrm{ml}$ contains moxifloxacin hydrochloride $5.45 \mathrm{mg}$ (equivalent to $5 \mathrm{mg}$ moxifloxacin base).

Determination of the pharmacokinetic parameters of moxifloxacin

The pharmacokinetic parameters of the drug were determined after oral administration of the drug. This study employed six healthy male volunteers. The drug concentration in the plasma samples was determined using both methods. The recorded plasma concentration versus time plots are shown in Fig. 5.

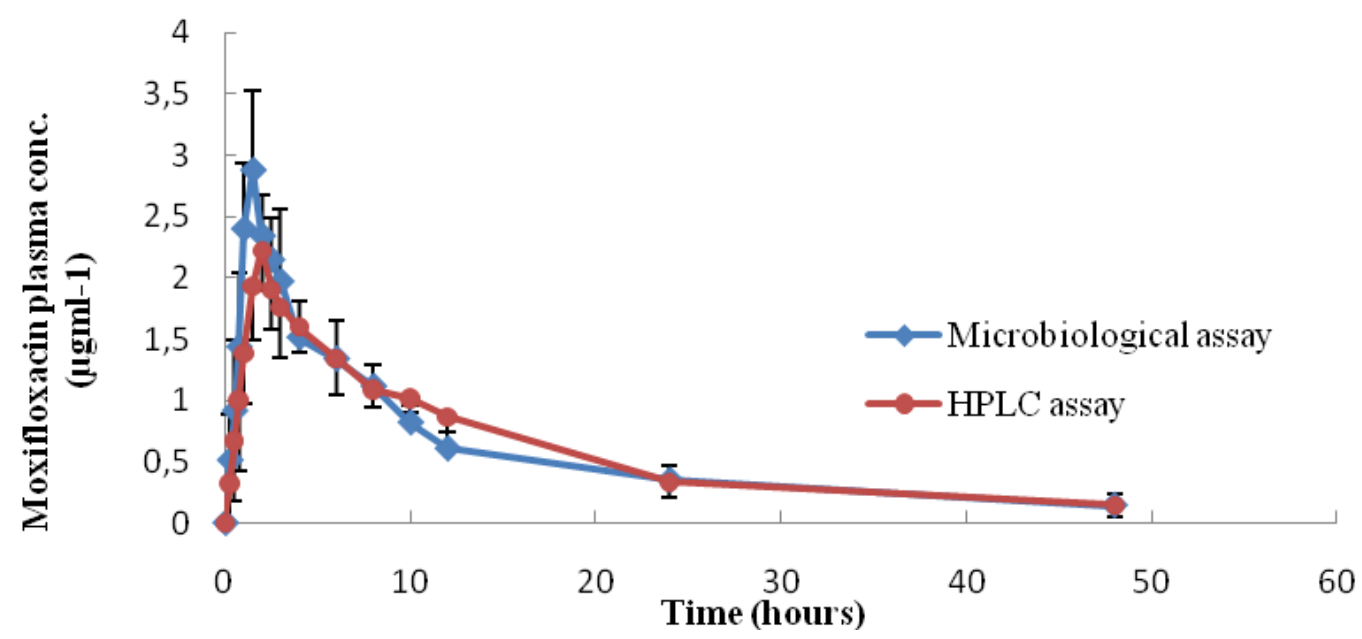

Figure 5. Mean Plasma conc. time profiles of moxifloxacin as determined by both microbiological assay \& HPLC assay following a single oral dose administration of one Avalox ${ }^{\circledR}$ film coated tablet (400 mg moxifloxacin). (Mean \pm S.D., $n=6$ )

The calculated pharmacokinetic parameters are presented in Table 6. The maximum plasma concentration $\left(\mathrm{C}_{\max }\right)$ of the drug was $3.14 \mu \mathrm{gml}^{-1}$ after HPLC determination and was $3.06 \mu \mathrm{gml}^{-1}$ after microbiological assay. These were shown to be statistically similar, indicating the suitability of both methods for determination of the pharmacokinetics of moxifloxacin. The other pharmacokinetic parameters revealed the same trend (Table 6). Pharmacokinetic parameters obtained using proposed methods are in agreement with those of the previously reported in the literature reports $(6,18,32)$, all summarized in Table 6 . 
Table 6. A comparison between the pharmacokinetic parameters of moxifloxacin obtained by microbiological \& HPLC methods with those reported previously

\begin{tabular}{ccccc}
\hline $\begin{array}{c}\text { Pharmacokinetic } \\
\text { parameters }\end{array}$ & $\begin{array}{c}\text { Values by microbiological } \\
\text { assay }\end{array}$ & Values by HPLC assay & \multicolumn{2}{c}{ Reported values } \\
\hline $\mathrm{C}_{\max }(\mu \mathrm{g} / \mathrm{ml})$ & $3.14 \pm 0.28$ & $3.06 \pm 0.26$ & $3.10 \pm 1.0^{*}$ & $3.34^{\ddagger}$ \\
$\mathrm{T}_{\max }(\mathrm{hr})$ & $1.50 \pm 0.32$ & $1.58 \pm 0.38$ & $1.4 \pm 0.20^{*}$ & $1.70^{\ddagger}$ \\
$\mathrm{AUC}_{0 \rightarrow \infty}(\mu \mathrm{g} . \mathrm{hr} / \mathrm{ml})$ & $30.8 \pm 3.60$ & $31.3 \pm 6.33$ & $36.1 \pm 9.10^{*}$ & $33.8^{\ddagger}$ \\
$\mathrm{T}_{1 / 2}(\mathrm{hr})$ & $14.04 \pm 1.71$ & $13.2 \pm 1.39$ & $11.5-15.6^{*}$ & $12.1^{*}$ \\
\hline
\end{tabular}

* Data obtained from (6)

* Data summarized from $(18,32)$

To further prove the similarity of both methods the correlation between the recorded concentrations in both cases was assessed (Fig. 6). This revealed good correlation between the recorded concentrations in each method with a correlation coefficient of 0.909. In earlier reports compared microbiological assays versus HPLC for the determination of FQs in plasma, Griggs and Wise achieved a coefficient of 0.956 (10), while other authors reported coefficients between 0.845 and $0.555(1,5,16)$.

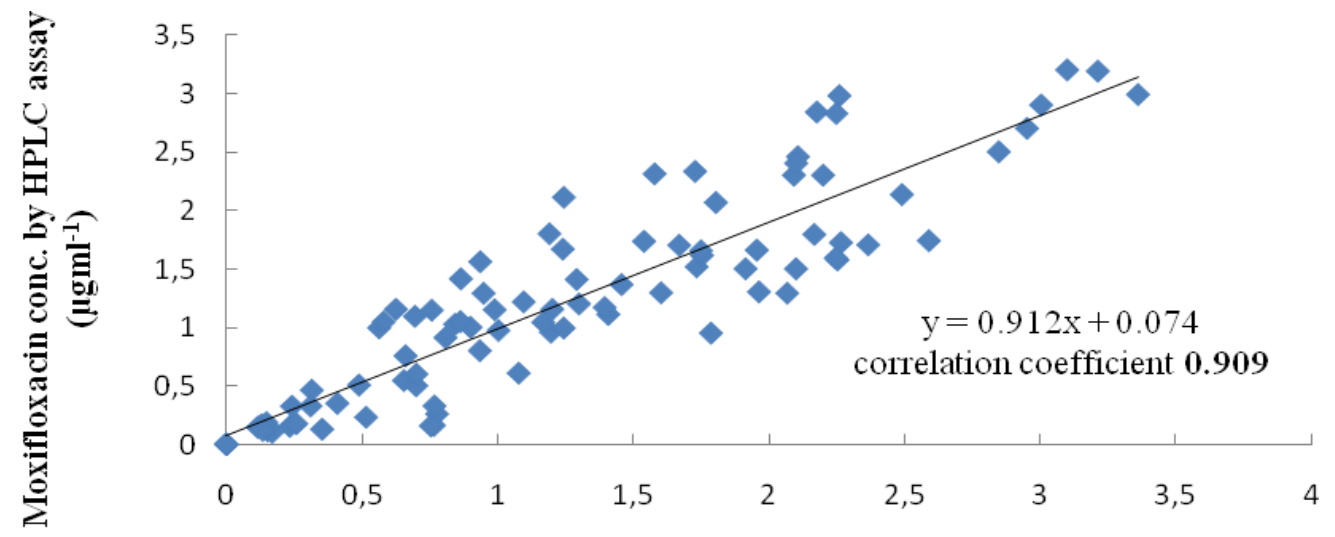

Moxifloxacin conc. by microbiological assay $\left(\mu \mathrm{gml}^{-1}\right)$

Figure 6. Correlation between microbiological and HPLC determinations of moxifloxacin concentration in all plasma samples $(\mathrm{n}=96)$

\section{CONCLUSION}

Although biological assays have a high variability incidence, the current study proved that the developed microbiological method for quantitative determination of moxifloxacin was accurate, precise, and sensitive. Thus, it is a valuable method for monitoring the quality of this drug in its different pharmaceutical preparations as well as studying its bioavailability and bioequivalence. Being similar to HPLC in efficacy the microbiological methods can provide an adequate determination of biological potency which offer additional advantage. Finally, the combination of assay methodologies designed to achieve similar results was a novel approach in an analytical laboratory and should be investigated to a greater extent.

\section{REFERENCES}

1. Auten, G.M.; Preheim, L.C.; Sookpranee, M.; Bittner, M.J.; Sookpranee, T.; Vibhagool, A. (1991). High-pressure liquid chromatography and microbiological assay of serum ofloxacin levels in adults receiving 
intravenous and oral therapy for skin infections. Antimicrob Agents Chemother 35, 2558-2561.

2. B.P. British Pharmacopeia, Volume IV $5^{\text {th }}$ ed., (2008). (general notices), Her Majesty's Stationary OfficeApendix XIV, London, UK, p. A323329.

3. Balfour, J.A.; Wiseman, L.R. (1999). Moxifloxacin. Drugs 57, 363-373; discussion 374.

4. Ball, P. (2000). The quinolones: history and overview. In: Andriole, V.T. (Ed.), The quinolones, 3rd ed. Academic Press, San Diego, p. 2-24.

5. Böttcher, S.; von Baum, H.; Hoppe-Tichy, T.; Benz, C.; Sonntag, H.G. (2001). An HPLC assay and a microbiological assay to determine levofloxacin in soft tissue, bone, bile and serum. J Pharm Biomed Anal 25, 197-203.

6. Clinical Pharmacology, (2009). www.rxlist.com/cgi/generic/ moxifloxacin-cp.htm.

7. Djurdjevic, P.; Ciric, A.; Djurdjevic, A.; Stankov, M.J. (2009). Optimization of separation and determination of moxifloxacin and its related substances by RP-HPLC. J Pharm Biomed Anal 50, 117-126.

8. European Pharmacopoeia, $4^{\text {th }}$ ed. (2002). Conseil de l'Europe, Strasbourg, 2.7.2., p.160-166.

9. Greco, G.M. (1997). Microbiological assay systems for the analysis of antibiotics in pharmaceutical formulations. (PhD. Dissertation. the State University of New Jersey. USA).

10. Griggs, D.J.; Wise, R. (1989). A simple isocratic high-pressure liquid chromatographic assay of quinolones in serum. J Antimicrob Chemother 24, 437-445.

11. Guerra, F.L.; Paim, C.S.; Steppe, M.; Schapoval, E.E. (2005). Biological assay and liquid chromatographic method for analysis of moxifloxacin in tablets. J AOAC Int 88, 1086-1092.

12. Hedaya, M.A. (2007). Basic pharmacokinetics. CRC Press, Boca Raton.

13. Hemanth Kumar, A.K.; Ramachandran, G. (2009). Simple and rapid liquid chromatography method for determination of moxifloxacin in plasma. J Chromatogr B Analyt Technol Biomed Life Sci 877, 12051208.

14. Hewitt, W. (2004). Microbiological assay for pharmaceutical analysis : a rational approach. Interpharm/CRC, Boca Raton.

15. Huber, L. (2003). Validation of analytical methods and processes. In: Nash, R.A., Wachter, A.H. (Eds.). Pharmaceutical process validation. 3 ed, New York, USA, p. 507-524.

16. Immanuel, C.; Hemanth Kumar, A.K. (2001). Simple and rapid highperformance liquid chromatography method for the determination of ofloxacin concentrations in plasma and urine. J Chromatogr B Biomed Sci Appl 760, 91-95.

17. Jain, G.K.; Jain, N.; Pathan, S.A.; Akhter, S.; Talegaonkar, S.; Chander, P.; Khar, R.K.; Ahmad, F.J.(2010). Ultra high-pressure liquid chromatographic assay of moxifloxacin in rabbit aqueous humor after topical instillation of moxifloxacin nanoparticles. J Pharm Biomed Anal
$52,110-113$.

18. Kim, M.K.; Nightingale, C.H. (2000). Pharmacokinetics and pharmacodynamics of the fluoroquinolones. In: Andriole, V.T. (Ed.). The quinolones.3rd ed. Academic Press, San Diego, p. 170-191.

19. Liang, H.; Kays, M.B.; Sowinski, K.M. (2002). Separation of levofloxacin, ciprofloxacin, gatifloxacin, moxifloxacin, trovafloxacin and cinoxacin by high-performance liquid chromatography: application to levofloxacin determination in human plasma. J Chromatogr B Analyt Technol Biomed Life Sci 772, 53-63.

20. Motwani, S.K.; Chopra, S.; Ahmad, F.J.; Khar, R.K. (2007). Validated spectrophotometric methods for the estimation of moxifloxacin in bulk and pharmaceutical formulations. Spectrochim Acta A Mol Biomol Spectrosc 68, 250-256.

21. Möller, J.G.; Stass, H.; Heinig, R.; Blaschke, G. (1998). Capillary electrophoresis with laser-induced fluorescence: a routine method to determine moxifloxacin in human body fluids in very small sample volumes. J Chromatogr B Biomed Sci Appl 716, 325-334.

22. Nguyen, H.A.; Grellet, J.; Ba, B.B.; Quentin, C.; Saux, M.C. (2004). Simultaneous determination of levofloxacin, gatifloxacin and moxifloxacin in serum by liquid chromatography with column switching. J Chromatogr B Analyt Technol Biomed Life Sci 810, 77-83.

23. Schlech, B.A.; Alfonso, E. (2005). Overview of the potency of moxifloxacin ophthalmic solution $0.5 \%$ (VIGAMOX). Surv Ophthalmol 50 Suppl 1, S7-15.

24. Stass, H.; Dalhoff, A.; Kubitza, D.; Schuhly, U. (1998). Pharmacokinetics, safety, and tolerability of ascending single doses of moxifloxacin, a new 8-methoxy quinolone, administered to healthy subjects. Antimicrob Agents Chemother 42, 2060-2065.

25. Tatar Ulu, S. (2007). High-performance liquid chromatography assay for moxifloxacin: pharmacokinetics in human plasma. J Pharm Biomed Anal $43,320-324$.

26. Trindade, M.A.G.; da Silva, G.M.; Ferreira, V.S. (2005). Determination of moxifloxacin in tablets and human urine by square-wave adsorptive voltammetry. Microchemical Journal 81, 209-216.

27. U.S. Food and Drug Administration, Guidance for Industry, Bioanalytical Method Validation, (2001). U.S. Department of Health and Human Services, Center for Drug Evaluation and Research (CDER), Centre of Veterinary Medicine (CVM), Rockville, USA Internet:// www.fda.gov/cvm.

28. Ulu, S.T. (2009). Spectrofluorimetric determination of fluoroquinolones in pharmaceutical preparations. Spectrochim Acta A Mol Biomol Spectrosc 72, 138-143.

29. US Pharmacopoeia \& National Formulary (2009). Second supplement, Moxifloxacin, Official Monographs, USP32-NF27, US Pharmacopeial Convention Inc., Rockville, p. 4264-4267.

30. US Pharmacopoeia \& National Formulary (2009). «81〉 AntibioticsMicrobial assays, USP32-NF27, US Pharmacopeial Convention Inc., 
Abdelaziz, A.A. et al.

Rockville, p. 86-93.

31. Wagenlehner, F.M.; Kees, F.; Weidner, W.; Wagenlehner, C.; Naber, K.G. (2008). Concentrations of moxifloxacin in plasma and urine, and penetration into prostatic fluid and ejaculate, following single oral administration of $400 \mathrm{mg}$ to healthy volunteers. Int J Antimicrob Agents
Determination of moxifloxacin in pharmaceutical preparations

31, 21-26.

32. Zhanel, G.G.; Noreddin, A.M. (2001). Pharmacokinetics and pharmacodynamics of the new fluoroquinolones: focus on respiratory infections. Curr Opin Pharmacol 1, 459-463.

(cc) BY-NC 1 All the content of the journal, except where otherwise noted, is licensed under a Creative Commons License 